\title{
AEM Study of Grain Boundary Precipitation Phenomena in Alloy 33 (Cr-Fe-Ni- N) Resulting from the Direct-Aging at $700{ }^{\circ} \mathrm{C}$
}

\author{
JC Spadotto $^{1}$; M Watanabe W IG Solórzano $^{1}$ \\ 1. Department of Chemical and Materials Engineering, PUC-Rio, Rio de Janeiro, Brazil \\ 2. Department of Materials Science and Engineering, Lehigh University, Bethlehem, PA
}

It is well established in several complex multicomponent alloy systems the concurrence of several modes of precipitation phenomena. Perhaps the most intriguing is the occurrence of concomitant general precipitation (GP, homogenous and heterogeneous) and discontinuous mode of precipitation (DP). While the former is controlled by lattice diffusion the latter is driven by grain boundary (GB) diffusion and migration. In this study, a DP phenomenon is focused, which takes place in an high performance super alloy 33 with austenitic matrix and chemical composition (wt.\%) of 32,75Cr$32,53 \mathrm{Fe}-31,35 \mathrm{Ni}-1,49 \mathrm{Mo}-0,54 \mathrm{Cu}-0,4 \mathrm{~N}-0,012 \mathrm{C}-0,63 \mathrm{Mn}-0,30 \mathrm{Si}$ during pre-determined heat treatments. The DP product then consists of alternated lamellae of a precipitated (equilibrium) phase and a depleted matrix, both growing in a cooperative fashion.

Figure 1A shows a DP colony with a concave-forward reaction front denoting strong chemical force acting at the GB and overcoming capillarity. Fig. 1B shows straight precipitate lamellae with a defined orientation relationship with the depleted matrix exhibiting a dislocation substructure, implying in some dynamic recovery upon annealing, taken by using a JEOL JEM-ARM200CF aberration-corrected scanning transmission electron microscope (STEM) at Lehigh. Fig. 1C is a set of X-ray maps taken from selected region in Fig. 2B around the lamellar precipitates, exhibiting enrichment of $\mathrm{Cr}$, depletion of $\mathrm{Ni}$ and free of $\mathrm{N}$, respectively. Figure 1D shows a bright-field (BF) STEM image of individual precipitate lamella, exhibiting localized strain fields at the interface and a detail of the interface in lattice image (Fig. 1E), containing dislocation, as seen the cores in darker contrast, accommodating the misfit to maintain a semi coherent interface.

Fig 2 presents a complex precipitation product at a different GB in this alloy upon direct aging at 700 ${ }^{\circ} \mathrm{C}$ for $100 \mathrm{~h}$ where different phases have nucleated and grown, driven by the diffusion of a moving GB. X-ray elemental maps show the degree of partition of different substitutional elements (Fe, Ni, $\mathrm{Cr}, \mathrm{Mo}$ ) and also interstitial N. In fact, one can identify more than two phases in this precipitate colony in which one phase contains $\mathrm{N}$. Contrary to findings in others investigations in $\mathrm{N}$ and $\mathrm{Cr}$ containing austenitic steels $[1,2]$, in this study it is confirmed that $\mathrm{Cr}$ can precipitate at GB in two fashions: as nitride and also free of $\mathrm{N}$. Moreover, $\mathrm{N}$ appears to have precipitated together with Mo. The nature of such precipitation, perhaps as Mo nitride (rather than $\mathrm{Cr}$ nitride) invites further investigation. In general, such complex GB precipitation products depend on the structure and thermodynamic properties of individual GBs [3]. [4]

References:

[1] M. Kikuchi, M. Kajihara and S.-K. Choi, Mater. Sci. Eng. A, vol. 146, pp. 131-150, 1991.

[2] P.A. Carvalho et al, Philosophical Magazine, vol. 88, n 2, pp. 229-242, 2008.

[3] I.G. Solórzano, G.R. Purdy and G. Weatherly, Acta Metallurgica, V. 32, pp. 1709-1717, 1984.

[4] The authors are grateful to CNPq (Brazil) and NSF-MWN (US:DMR-0303429) joint CIAM Program. 

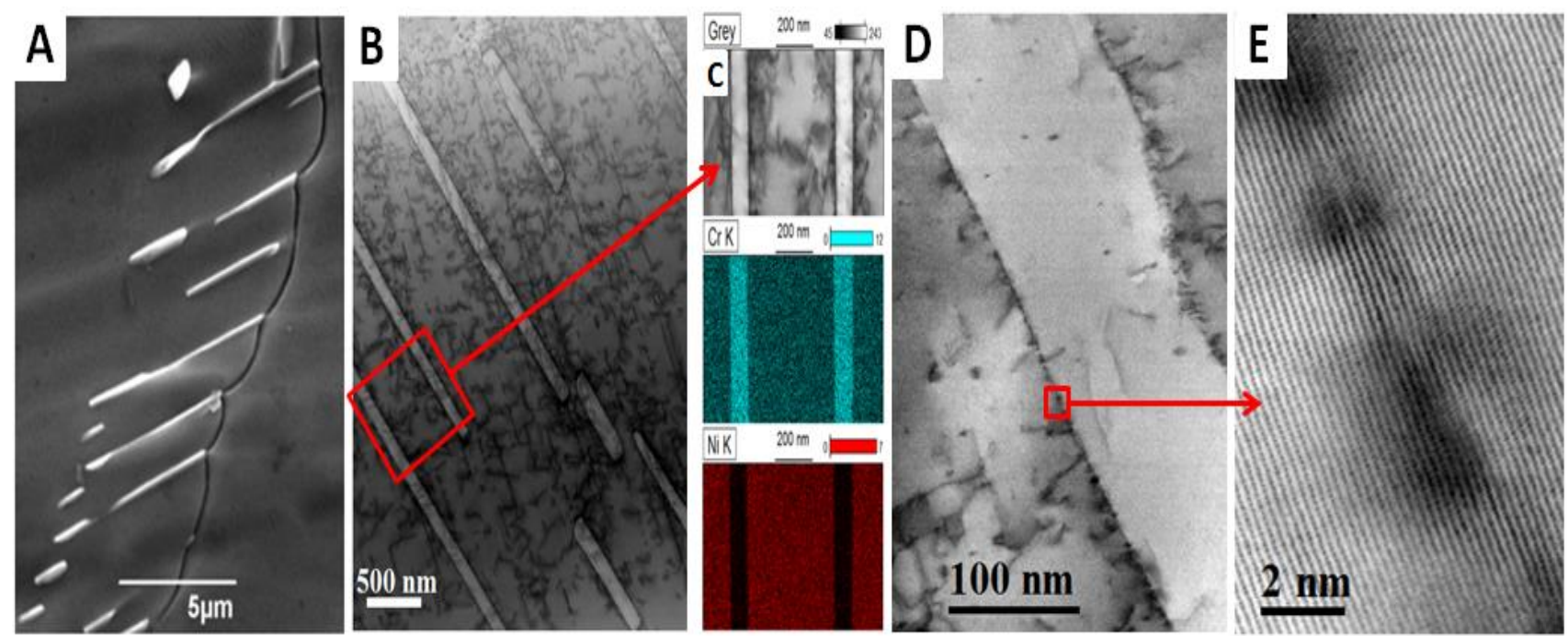

Figure 1. Alloy 33 microstructure after direct-aging at $700{ }^{\circ} \mathrm{C}$ for $100 \mathrm{~h}$; (A) an image of a DP colony taken by a scanning electron microscope; (B) a BF-STEM image of lamellae and residual dislocations; (C) a set of X-ray elemental maps of lamellae marked in the red box indicating that the lamellae are rich in $\mathrm{Cr}$, depleted in $\mathrm{Ni}$ and free of $\mathrm{N}$; (D) a BF-STEM image of a precipitate lamella; (E) an atomic-resolution BF-STEM image of precipitate/depleted matrix interface containing misfit dislocations.
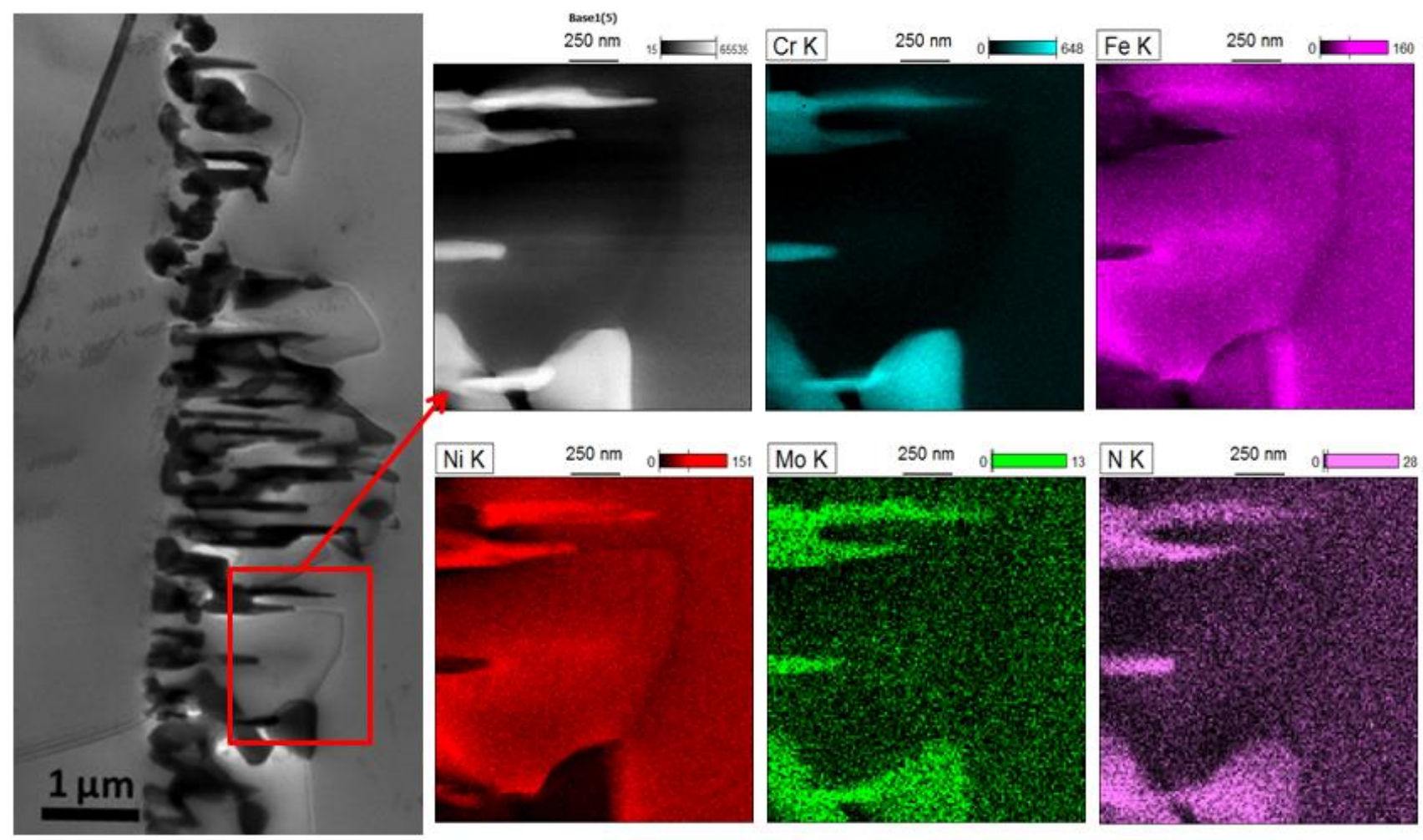

Figure 2. A BF-STEM image of a coarsened DP colony resulting from direct-aging at $700{ }^{\circ} \mathrm{C}$ for $100 \mathrm{~h}$ and an ADF-STEM image of the boxed area with corresponding elemental mapping of $\mathrm{Cr}, \mathrm{Fe}$, $\mathrm{Ni}$, Mo and N, identifying different phase in the same DP colony. 